\title{
PROFITABLE HIGH-SPEED PASSENGER VESSEL FOR SHORT LINES AT SEA
}

\author{
Victor A. Dubrovsky ${ }^{* 1}$ 伲 \\ ${ }^{* 1}$ Dr. Scs., Dr. Phil., Russia
}

DOI: https://doi.org/10.29121/granthaalayah.v8.i6.2020.453

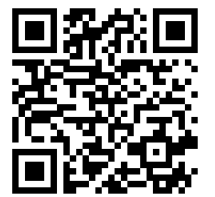

Article Type: Research Article

Article Citation: Victor A. Dubrovsky. (2020). PROFITABLE HIGH-SPEED PASSENGER VESSEL FOR SHORT LINES AT SEA. International Journal of Research GRANTHAALAYAH, 8(6), 142-149. https://doi.org/10.29121/granthaa layah.v8.i6.2020.453

Received Date: 08 May 2020

Accepted Date: 26 June 2020

Keywords:

High-Speed Vessel

Passenger Vessel

Outrigger Bessel

Designing

Seakeeping

Economy Characteristics

\section{ABSTRACT}

The paper [1] had presented an alternative option of outrigger highspeed passenger vessel for short lines. Such ships can compete with existed ones from economy point of view if the firsts will have minimal cost of building and minimal operation price, firstly - because of minimal outlay of fuel, but for comparable service speed and capacity of passengers. Besides, usually small enough vessels are strongly affected by weather, by waves in main. It means, seaworthiness of such ships is a permanent problem if they must operate at more or less severe conditions of weather.

Two newly proposed options of outrigger ships are described below: the first has small water-plane area of the main hull bow, and the second has small water-plane area of the main hull as a whole. The selection of the main dimensions are shown in main, the results are discussed from seaworthiness point of view. Both new options are recommended for further designing, including researching of motion characteristics and possible economy results.

\section{INTRODUCTION}

Evidently, a most profitable vessel must have minimal price of building and exploitation - with the needed service speed, passenger capacity and fulfilled rules of safety and comfort.

Today some high-speed passenger mono-hulls with shallow-immersed foils, in main - "Meteor" series, work at short enough lines at rivers and lakes of Russia. There ships, with service speed 30-32 knots and passenger capacity about 120 persons, were built some years ago by Soviet river yards. The hull structures of these ships were manufactured from sea light alloy, and their cost were paid by service incomes at long times of exploitation. It means the part of today expenses of hull cost is small enough. Besides, as any foiled ships, "Meteors" have good enough performance, see below.

But there is a problem of these ships changing by the vessels of the next generation. And the existed vessels are the base of economical comparison for any new vessels. The paper [1] contains a brief description of the newly proposed ship for the same purposes. The main ideas of the new ship initial demands are: - twice smaller power of the main engine; i.e. twice smaller fuel outlay and corresponded decreasing of fuel cost; it means the service speed decreasing at about $20 \%$ for the comparable displacement; - for ensuring the same passenger flow, the new vessel

(C) 2020 The Author(s). This is an open access article distributed under the terms of the Creative Commons Attribution License, which permits unrestricted use, distribution, and reproduction in any medium, provided the original author and source are credited. 
will have passenger capacity bigger at 20\%, i.e. about 150 persons. The table 1 contains the main dimensions and general characteristics of the vessel "Meteor" type and the proposed vessel [1].

Table 1: Main dimensions and general characteristics of the compared vessels.

\begin{tabular}{|l|c|c|}
\hline Ship purpose & \multicolumn{2}{|c|}{ Short tourist lines } \\
\hline Ship type & Mono-hull with shallow-immersed foils & Outrigger ship \\
\hline Full displacement, $\mathrm{t}$ & 53.4 & Abt. 60 \\
\hline Light ship, $\mathrm{t}$ & 36.4 & Abt. 40 \\
\hline Overall length, $\mathrm{m}$ & 34.6 & 38 \\
\hline Overall beam, $\mathrm{m}$ & 9.5 & 9.5 \\
\hline Hull depth, $\mathrm{m}$ & 5.25 & 5.25 \\
\hline Passenger capacity, pers & 120 & 150 \\
\hline Draft at full displacement, $\mathrm{m}$ & 2.35at rest, 1.2 at full speed & Overall 2.0 \\
\hline Above water height, $\mathrm{m}$ & 5.63 at slow speed, 6.78 at full speed & 4.5 \\
\hline Engine power, $\mathrm{kWt}$ & $2 \times 800$ & $1 \times 800$ \\
\hline Full speed, kn & 38 & Abt. 32 \\
\hline Service speed, kn & $30-32$ & $26-28$ \\
\hline Fuel supply, $\mathrm{t}$ & 3.2 & 1.6 \\
\hline Range, $\mathrm{nm}$ & 300 & 300 \\
\hline
\end{tabular}

Some details of the proposed options designing are shown below.

\section{HULL LENGTHENING}

One of the main characteristics, which act to the performance of high-speed vessels at thr transient speed mode, is relative length of hull $(\mathrm{s}), \mathrm{l}=\mathrm{L} / \mathrm{V}^{1 / 3}$. Figure 2 shows some statistic data on the relative length influence to the residual resistance coefficient of a hull, [2].

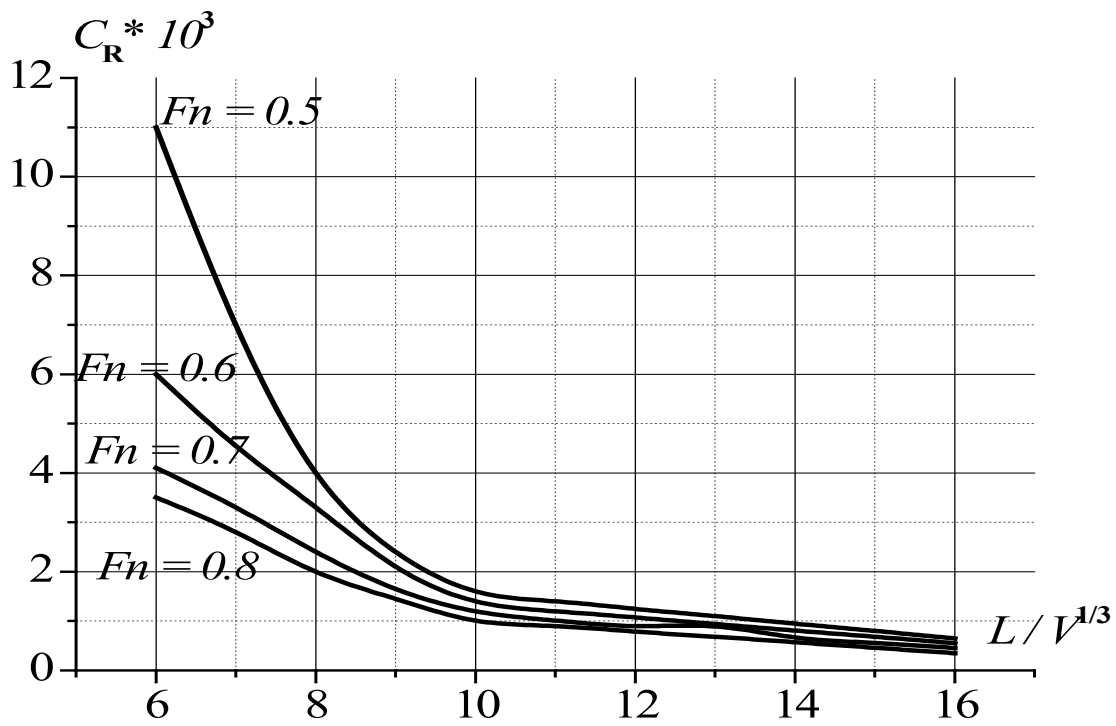

Figure 2: Residual resistance coefficient of a hull versus its relative length [2].

Evidently, the influence of relative length is big enough, only if the length is no more, than 10 . Further growth of the relative length means a notable drop of its influence. Therefore, the main hull relative length can be selected equal to 10 for betters performance of the proposed outrigger vessel. 


\section{SELECTION OF OUTRIGGER SHAPE}

Evidently, the outriggers must have round- bottom or chine hulls. And small enough vessel will have short enough outriggers. But the vessel speed will be high enough. It means high enough relative speed by the outrigger length (Froude number). If the Froude number is equal to 1 or more, the moving round-bottom outriggers will be strong enough sources of sprays, i.e. will have big enough own resistance.

Than the chine shape seems better one for the outriggers of examined vessels. But there is the second problem: the outriggers, are connected with the main hull, can`t change their attitude (dynamic trim and average draft), i.e they will be flowed as fixed bodies. The circumstance must be taken into account at the estimation of outrigger own resistance.

The paper [3] allows exact enough estimation of the resistance of fixed chine hulls.

\section{THE OTHER OVERALL DIMENSIONS}

These dimensions are selected with an assumption of simultaneously work with existed vessels at the same lines and near the same piers. It defines the overall beam $9.5 \mathrm{~m}$; and the overall draft was selected equal to $2 \mathrm{~m}$ instead of $2.35 \mathrm{~m}$ of "Meteor" type vessels.

Passenger deck area was selected for the same standard, as on the existed vessels; and outrigger length and water-plane area was selected for ensuring the needed transverse initial stability as a passenger ship.

\section{SEAWORTHINESS INCREASING}

One of the problems of small sized high-speed vessel designing is ensuring of seaworthiness, because small ships are strongly influenced by waves at sea. And the main disadvantage of any ships with shallow-immersed foils is sufficiently limited seakeeping.

Figure 3 [4] contains some general statistic data on the main seakeeping characteristic of various passenger ships: values of vertical acceleration in head seas.

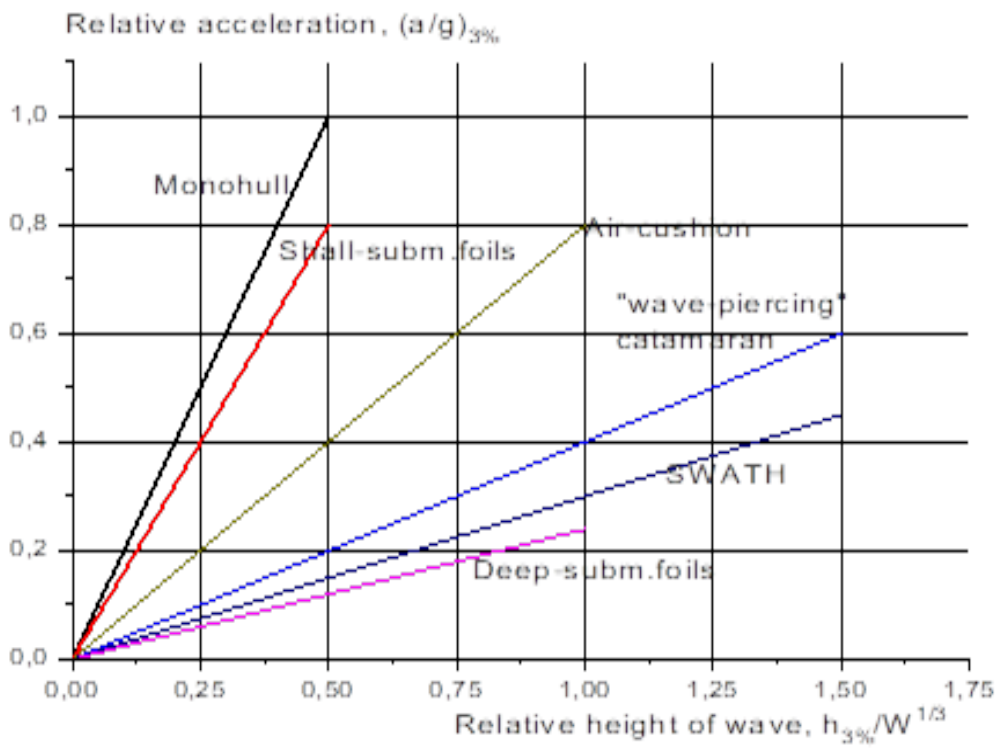

Figure 3: Brief comparison of vertical accelerations of various vessels at head waves.

Evidently, the best seaworthiness can be ensured by vessels with deeply-submersed automatically controlled foils and or by vessels with small water-plane area, SWA vessels. The first ones are expensive enough and usually need for big enough depth of harbors. Than such foiled vessels are not examined below. 
Figure 4 shows the difference of achievable speeds of two twin-hull vessels of the same displacement (100 t), but various shape of hulls: usual catamaran and ship with small water-plane area (SWATH, duplus). Both ships have nothing devices of motion mitigation.

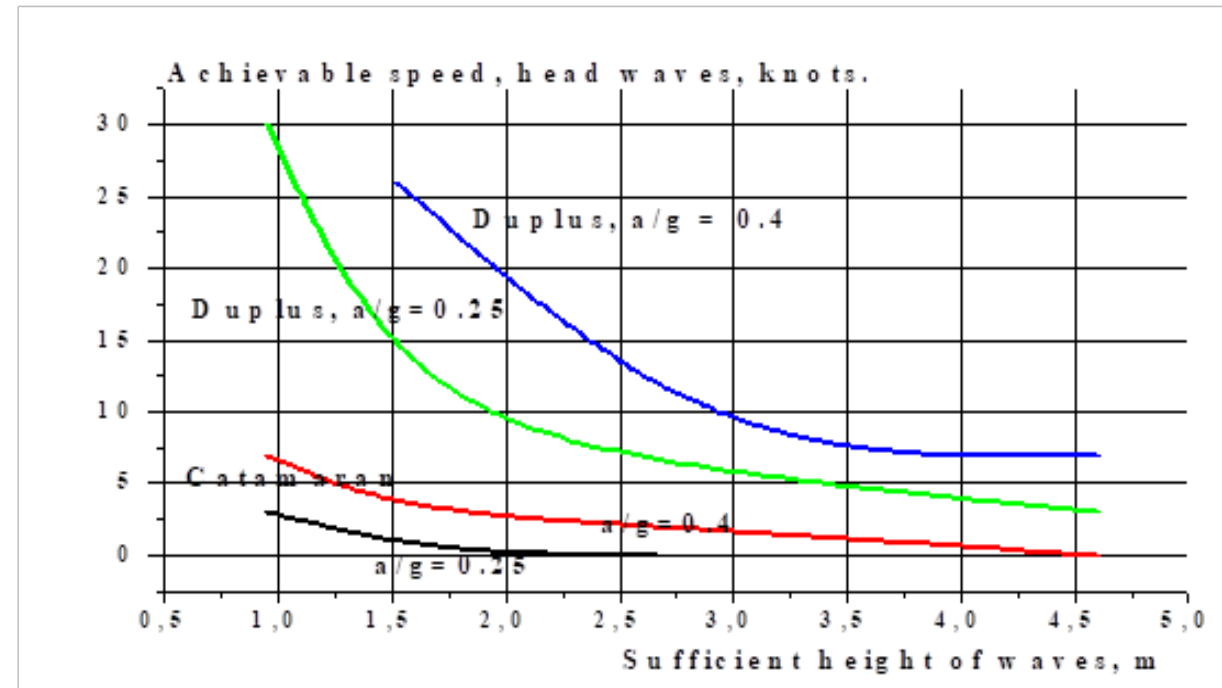

Figure 4: Achievable speeds of two vessels at various selected standards of seakeeping (vertical accelerations), [5].

Evidently, usual shape of hulls can't ensure permissible speeds at the selected values of vertical accelerations.

It must be noted, all methods of motion mitigation are especially effective for ships with small water-plane area because of habitual decreased external loads of them. For example, Fig. 5 shows the effect of controlled foils for motion mitigation. It is some test results of 7-t self-propelled model of twin-hull SWA ship in natural waves.

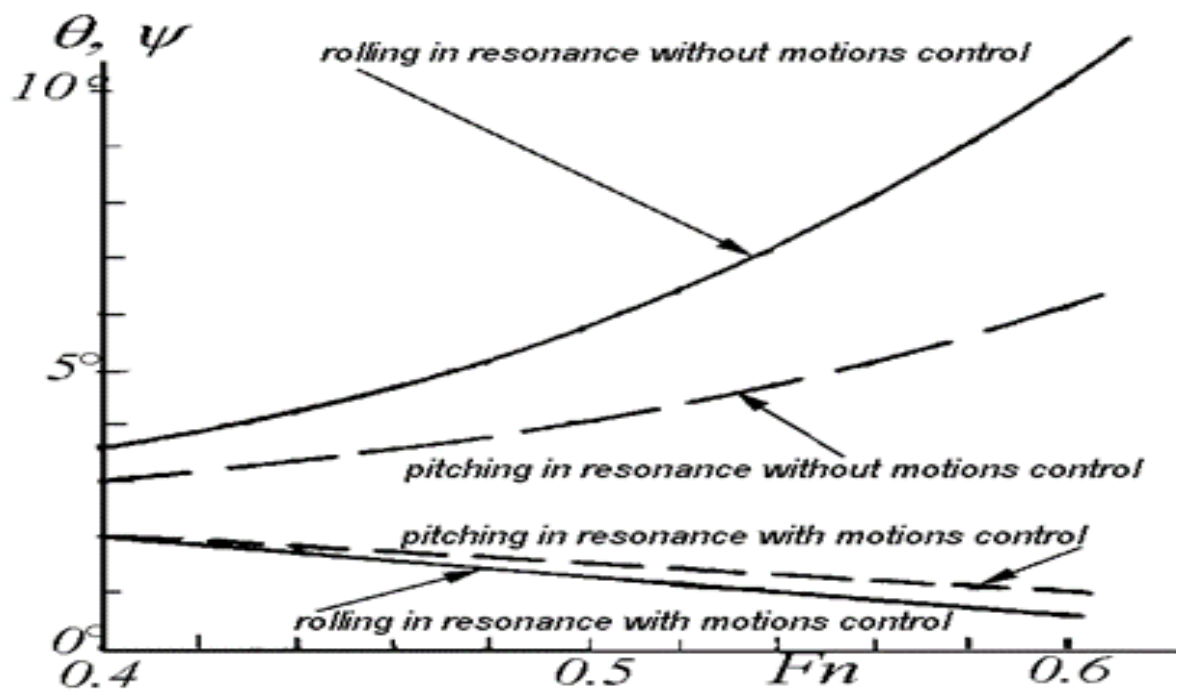

Figure 5: Pitch and roll of the 7-t self-propelled twin-hull model with small water-plane area.[6]

Most possible, even small water-plane area of small enough examined vessel can`t ensure the desired characteristics at waves, for example, Sea State 4. If it will be so, motion mitigation systems can be necessary for needed level of seaworthiness.

The paper [1] contains a note on the possibility of examination of so-named "semi-SWA" option and SWA ship option. Evidently, a "semi-SWATH" small-sized vessel will be better, than the comparable vessel with usual hull shape, but worse, than "pure" SWA vessel. 
Two newly proposed options of the high-speed passenger vessel for 150 passengers are shown and briefly discussed below.

\section{NEWLY PROPOSED OPTIONS}

Two newly proposed options are shown below. The first one have only bow with decreased area of water-plane; it is so named "semi-SWA" vessel. The second have minimal area of water-plane, it is "pure" SWA ship. Both new options have the same engine power $800 \mathrm{kWt}$, passenger capacity150 persons, overall beam ( $9.5 \mathrm{~m})$, overall draft $2.0 \mathrm{~m}$, draft at middle $1.5 \mathrm{~m}$, overall draft $2.0 \mathrm{~m}$. The main dimensions of both new options are selected with their specificity examination.

\section{SEMI-SWA VESSEL}

Such vessel will have the same lengthening of the main hull, as the previously examined one [1]. Figure 6 shows the hull shape of such vessel.

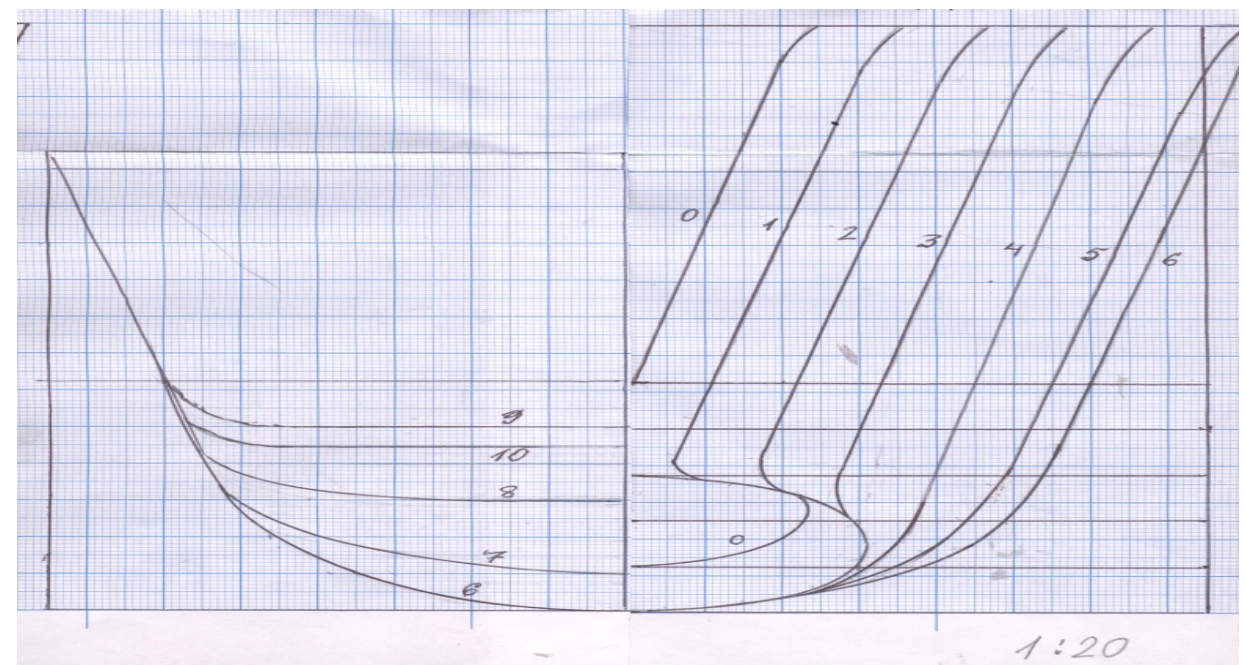

Figure 6: A sketch of hull shape of semi-SWA vessel.

Evidently, such hull has straight water-lines, and the bigger frame is \#6. Hull length at design water-plane is equal to $40 \mathrm{~m}$, it means the relative length about 9.7; hull beam is $3 \mathrm{~m}$. The semi-SWA vessel differs from the previously proposed option [1] only by the bow shape of the main hull. It means both options have the same sketch of general arrangement. Corresponded sketch of general arrangement is shown by Figure 7.

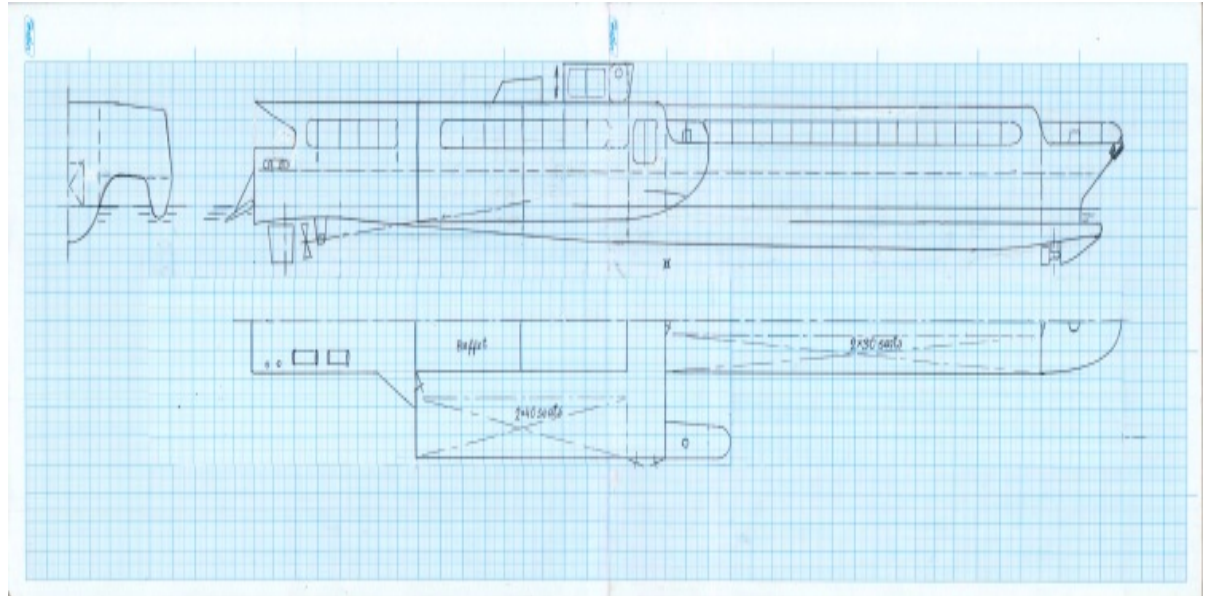

Figure 7: Sketch of semi-SWA vessel general arrangement. 


\section{SWA OPTION}

The second newly proposed option will have "pure" shape with small water-plane area (SWA ship). Figure 8 shows the main hull shape of the second newly proposed vessel.

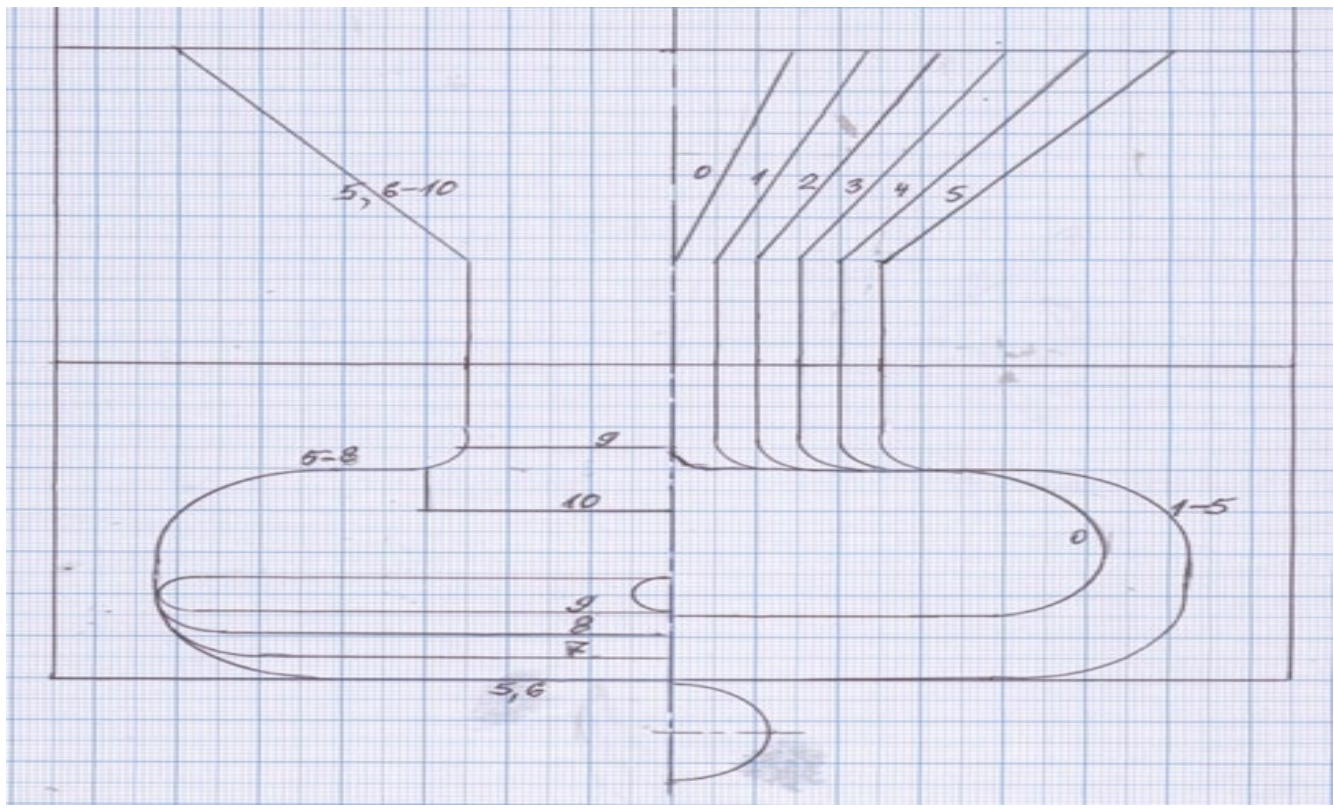

Figure 8: Main hull shape of SWA vessel

The vessel with small water-plane area usually has bigger fullness of the hull; then the hull length must be smaller, than of usual shape option. The hull length of the second new option is $32 \mathrm{~m}$, it means the main hull relative length about 7.6.

Figure 9 shows the sketch of general arrangement of the vessel with small water-plane area of the main hull. Shape and dimensions of outriggers are the same for both new options.

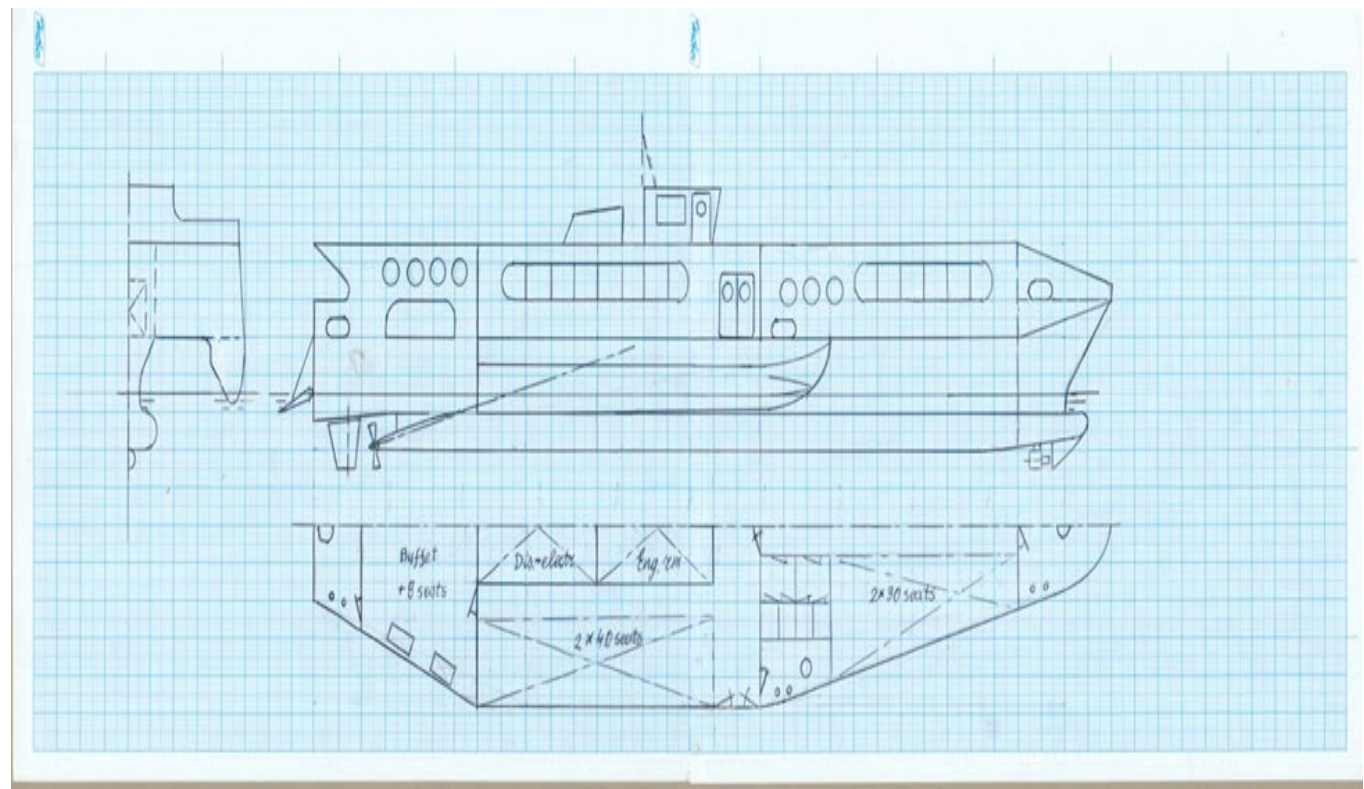

Figure 9: Sketch of general arrangement of SWA vessel.

The angle of main shaft inclination here is equal to 15 degrees. It allows to arrange the main engine at bigger height, but at the same place near the outriggers. 


\section{ADDED SYSTEMS}

It is supposed, the new ships will have the system of bow rudder-propeller VL-50, company Veth Propulsion, added diesel-generator $100 \mathrm{kWt}$; the rudder-propeller is placed behind the bow bulb. The system is intended for better maneuverability at slow speeds and as emergency propulsor.

Besides, referring to the results of designing, model tests and seakeeping demands, the ships can have systems of motion mitigation: automatically controlled stern flap and bow controlled foils with corresponded system of control.

\section{MAIN DIMENSIONS AND GENERAL CHARACTERISTICS OF THE PROPOSED VESSELS}

The table 2 contains a brief comparison of the selected characteristics (zero approximation).

Table 2: Main dimensions and general characteristics of two newly proposed vessels.

\begin{tabular}{|c|c|c|}
\hline Ship purpose & \multicolumn{2}{|c|}{ Short tourist lines } \\
\hline Ship specificiuty & $\begin{array}{l}\text { Outrigger ship with semi-SWA } \\
\text { main hull. }\end{array}$ & $\begin{array}{c}\text { Outrigger ship } \\
\text { With SWA main hull }\end{array}$ \\
\hline Full displacement, light ship, $\mathrm{t}$ & Abt. 73 , abt.60 & Abt. 75 , abt.63 \\
\hline $\begin{array}{l}\text { Achievable speed at head Sea State } 4 \text { for } \\
\text { vertical acceleration } 0.25 \mathrm{~g}\end{array}$ & Abt. 5 & Abt.15 \\
\hline Overall length, overall beam, $\mathrm{m}$ & $40 ; 9.5$ & $32 ; 9.5$ \\
\hline Relative area of water-plane, $\mathrm{S}_{\mathrm{WP}} / \mathrm{V}^{2 / 3}$ & 4.3 & 1.4 \\
\hline Hull depth, m & 5.25 & 5.25 \\
\hline Passenger capacity, pers & 150 & 150 \\
\hline Draft at full displacement, $\mathrm{m}$ & Overall 2.0 & Overall 2.0 \\
\hline Above water height, $\mathrm{m}$ & 4.5 & 4.5 \\
\hline Engine power, kWt & $1 \times 800$ & $1 \times 800$ \\
\hline Full speed of light ship, kn & Abt. 26 & Abt.25 \\
\hline Service speed at full displacement, kn & Abt.22 & Abt.21 \\
\hline Fuel supply, $\mathrm{t}$ & 3.2 & 1.6 \\
\hline Range, $\mathrm{nm}$ & 300 & 300 \\
\hline
\end{tabular}

Existed today ship ("Meteor" type) has service speed about 30 knots. It means service speed of the compatible vessels must be about $24 \mathrm{kn}$. But today rough estimation of achievable displacement and service speed of the newly proposed vessels shows smaller speeds, if the engine power will be $800 \mathrm{kWt}$.

Approximate estimation of power shows the need of $990 \mathrm{kWt}$ for semi-SWA vessel and $1120 \mathrm{kWt}$ for SWA vessel, if the service speed 24 knots will be defined as necessary one. It must be noted even increased power is smaller, than the engine power of the existed ship ( $2 \times 800 \mathrm{kWt})$.

More detail estimation of possible displacement and service speed can be carried out at the further stages of designing. Moreover, the engine power can be increased, if it will be desired.

\section{THE PROBLEMS OF COMPARISON}

The table 2 contains the values of relative water-plane area. Evidently the semi-SWA option has the area at about $20 \%$ smaller, as usual shape vessels. Usually it means the corresponded decreasing of all kinds of motions. In addition, the table contains the estimated achievable speed at head waves Sea State 4, if the bow vertical acceleration is $0.25 \mathrm{~g}$. Evidently, semi-SWA vessel can`t ensure the same level of achievable speed in waves, as SWA option, for selected standard of acceleration. But semi-SWA vessel has some other advantages in the comparison with SWA option. Some more detail researching is needed for more based selection of option. 
Besides, some separate problems will be examined for the exact comparison of vessels from seakeeping point of view.

1) Exact definition of the permissible wave height (together with its repeatability at the examined seas) is necessary for any ship comparison from seaworthiness point of view.

2) Selection of the desired set of seakeeping standards is needed for exact enough comparison.

3) More exact, as usually, taking into account real time of service at waves is needed for based enough comparison of economy characteristics of examined ships. Most simple and evident method of seakeeping comparison was proposed by the article [7]. The result of such calculations is definition of average time of selected standards full fulfilling of seakeeping by examined ships at the desired seas. It allows definition of real time of full operability of the examined vessel, the time must be used for real cost definition of a hour of service at the examined seas.

\section{CONCLUSION, RECOMMENDATION}

1) Two high-speed passenger outrigger vessels were proposed as the alternatives of existed ships with shallow-immersed foils for wider exploitation at seas.

2) Both new options are recommended for further designing, including seakeeping model tests and estimation of economic characteristics with seakeeping taken into account.

\section{SOURCES OF FUNDING}

None.

\section{CONFLICT OF INTEREST}

None.

\section{ACKNOWLEDGMENT}

None.

\section{REFERENCES}

[1] Dubrovsky V., "High-Speed Outrigger Vessel as a Competitor of Mono-Hull with Shallow-Immersed Foils", International Journal of Emerging Technology \& Advanced Engineering (ISSN 2250-2459), Volume 10, Issue 05, May, 2020.

[2] Dubrovsky V., "Ships with Outriggers", ISBN 0-9742019-0-1,2004, Backbone Publishing Co., Fair Lawn, USA, $88 \mathrm{p}$.

[3] Tikhonov A. "Planing of keeled plate...", Proceedings of TSAGI, issue 968, 1965, Moscow, in Russian.

[4] Dubrovsky V., "Specificity \& designing of multi-hull ships \& boats", 2016, Nova Science Publishers, ISBN 9781634846158, USA, 210 p.

[5] Dubrovsky V., Lyakhovitsky, A., "Multi-hull ships”, 2001, ISBN 0-9644311-2-2, Backbone Publishing Co., Fair Lawn,USA, 495 p

[6] Dubrovsky V., Matveev K., Sutulo S., 2007, "Ships with small water-plane area”, Backbone Publishing Co., ISBN-13978-09742019-3-1, Hoboken, USA,256 p.

[7] Dubrovsky V., “Complex comparison of seakeeping: method and example”, 2000, Marine Technology and SNAME News, vol. 37, \# 4, October, pp.223 - 229. 